\title{
AN INVESTIGATION OF CROSS-BOREHOLE GROUND PENETRATING RADAR MEASUREMENTS FOR CHARACTERIZING THE 2D MOISTURE CONTENT DISTRIBUTION IN THE VADOSE ZONE
}

\author{
Lee Paprocki, New Mexico Institute of Mines and Technology, Box 2628, \\ Socorro, NM 87801 \\ David Alumbaugh, Sandia National Laboratories, PO Box 5800, MS 0750, \\ Albuquerque, NM 87185
}

\begin{abstract}
The use of cross-borehole ground penetrating radar (GPR) imaging for determining the two dimensional (2D) in situ moisture content distribution within the vadose zone is being investigated. The ultimate goal is to use the GPR images as input to a 2D hydrologic inversion scheme for recovering the van Genuchten parameters governing unsaturated hydraulic flow.

Initial experiments conducted on synthetic data have shown that at least in theory, cross-borehole GPR measurements can provide realistic estimates of the spatial variation in moisture content that are needed for this type of hydrologic inversion scheme. However, the method can not recover exact values of moisture content due to 1) the break down of the empirical expression often employed to convert GPR velocity images to moisture content, and 2) the smearing nature of the imaging algorithm.

To test the applicability of this method in a real world environment, crossborehole GPR measurements were made at a hydrologic/ geophysical vadose zone test site in Socorro, New Mexico. Results show that the GPR images compare well with the uncalibrated borehole neutron $\log$ data. GPR data acquisition will continue once an infiltration test has started, and the results from these measurements will be employed in a 2D hydrologic inverse scheme.
\end{abstract}

\section{INTRODUCTION}

Unsaturated hydraulic conductivity governs unsaturated flow within the vadose zone. The spatial variability of this property is often estimated from measurements of samples collected at a limited number of boreholes and then extrapolating the results across the region of interest. Often this leads to a detailed knowledge of how the conductivity varies with depth, but little information on how it varies laterally. Also, the sampling process will often disturb the material which can lead to inaccurate measurements. A non destructive technique for estimating the hydrological properties within the vadose zone, in situ, could lead to better estimates of contaminant travel times, pathways, and better design of waste containment and/or remediation methods.

Ground penetrating radar (GPR) is a high resolution, rapid acquisition geophysical method that can obtain detailed estimates of the electromagnetic (EM) wave velocity within the earth. The EM wave velocity depends primarily upon the moisture content (Topp et al., 1980). Thus GPR measurements can be used to produce images that predict the two dimensional distribution of in situ moisture content. The ultimate goal is to then 


\section{DISCLAIMER}

This report was prepared as an account of work sponsored by an agency of the United States Government. Neither the United States Government nor any agency thereof, nor any of their employees, make any warranty, express or implied, or assumes any legal liability or responsibility for the accuracy, completeness, or usefulness of any information, apparatus, product, or process disclosed, or represents that its use would not infringe privately owned rights. Reference herein to any specific commercial product, process, or service by trade name, trademark, manufacturer, or otherwise does not necessarily constitute or imply its endorsement, recommendation, or favoring by the United States Government or any agency thereof. The views and opinions of authors expressed herein do not necessarily state or reflect those of the United States Government or any agency thereof. 


\section{DISCLAIMER}

Portions of this document may be illegible in electronic image products. Images are produced from the best available original document. 
use these estimates of moisture content within a 2D hydrologic inverse model in order to obtain the van Genuchten parameters (van Genuchten, 1980) that govern unsaturated hydraulic flow.

Using GPR to obtain in situ moisture content is a fairly new application. Eppstein and Dougherty (1998) have used cross-borehole GPR to compare velocity changes before and after infiltration in order to image relative moisture changes. In addition, Greaves et al. (1996) have utilized surface GPR to obtain subsurface water content. Hubbard et al. (1997) used surface GPR along with conventional hydrological data to better estimate saturation and permeability. However, until now cross-borehole GPR has not been thoroughly examined as a method to estimate absolute in situ moisture content.

To examine the use of cross-borehole GPR for establishing better in situ estimates of the van Genuchten parameters, we have established a four-phased process: 1) conduct numerical experiments to quantify the ability of cross-borehole GPR to estimate the in situ moisture content; 2) conduct an initial cross-borehole GPR survey at a test site to evaluate the method's ability to image moisture content under realistic conditions; 3) collect cross-borehole GPR data during an infiltration experiment to monitor changes in moisture content over time; and 4) incorporate the moisture content images obtained during infiltration into a hydrologic inversion scheme. In this paper we will address advancements made under points 1) and 2).

\section{GPR MEASUREMENT SYSTEM AND DATA PROCESSING}

In this study we have employed the Sensors and Software Pulse Ekko 100 GPR system in the cross-borehole configuration. In this configuration an electric dipole transmitter in one borehole transmits a pulse, with the direct and scattered EM wavefield measured by a second electric dipole antenna positioned in a second borehole located a few meters away from the first. For a given source-receiver pair, the datum that we are interested in is the travel time of the direct wave from the source to the receiver. This yields an estimate of the EM wave velocity of the material between boreholes. By making measurements of the travel time for multiple source and receiver pairs, we can tomographically reconstruct the $2 \mathrm{D}$ velocity distribution between boreholes.

The GPR results presented in this paper have been processed in the following manner. First the data are calibrated using a small subset of data that are collected with both the source and receiver in the air. Second the first arrival, or EM wave travel times are 'picked' using Sensors and Software's Ekko42 data processing package. Third the travel time data are inverted using the scheme of Aldridge and Oldenburg (1993) to produce a 2D image of EM wave velocity. This scheme imposes constraints on the model to produce an estimate of the velocity that varies smoothly from one point to another within the image domain. In addition, the tomography code uses a finitedifference travel time computation of Vidale (1988), rather than a ray tracing scheme to compute travel times between the source and receivers. Fourth, the velocity image is converted to an image of apparent dielectric constant, and then to moisture content. The conversion to apparent dielectric constant uses the fact that for materials of relatively low 
electrical conductivity (say electrical conductivities less than $.03 \mathrm{~S} / \mathrm{m}$ ), the apparent dielectric constant is given by the expression

$$
\varepsilon_{a}=\sqrt{c / v}
$$

where $\varepsilon_{a}$ is the apparent dielectric constant which is dimensionless, $c$ is the velocity of light in a vacuum $\left(\varepsilon_{a}=1\right)$, and $v$ is the EM velocity of the medium as determined from the image. Both $c$ and $v$ have dimensions of $\mathrm{m} / \mathrm{ns}$. Note that as the electrical conductivity increases above $0.03 \mathrm{~S} / \mathrm{m}$, this expression rapidly becomes approximate. For example at $0.05 \mathrm{~S} / \mathrm{m}$ the error is $2 \%$, while for a conductivity of $0.1 \mathrm{~S} / \mathrm{m}$ the error is $8 \%$. The apparent dielectric values are then converted to moisture content via Topp's Equation (Topp et al., 1980). Topp's equation is an empirical relationship between dielectric constant and the volumetric water content of porous sediments. It was derived by making laboratory measurements of the dielectric constant on a number of different soil samples over a wide range of saturation, and then fitting the resulting data with a third order polynomial. Topp's equation is given as

$$
q=-5.3 \times 10^{-2}+2.9 \times 10^{-2} \varepsilon_{a}-5.5 \times 10^{-4} \varepsilon_{a}^{2}+4.3 \times 10^{-6} \varepsilon_{a}^{3}
$$

where $q$ is the fractional volumetric water content. Note that this expression becomes zero for $\varepsilon_{a} \cong 1.8$. Also notice that this expression does not require any knowledge of the rock. These properties will become important later when we discuss the accuracy of this expression for low moisture contents, as well as its usefulness.

\section{THEORETICAL EXAMPLE}

Initial experiments were conducted on a synthetic data set. These have shown that, at least in theory, cross-borehole GPR measurements can provide realistic images of the spatial variation in moisture content needed for hydrologic inversion schemes currently being developed (e.g. Zhang and Yeh, 1997). In Figure 1a we have plotted a synthetic model in terms of its EM wave velocity, electrical conductivity $(\sigma)$ and apparent dielectric constant. In this figure regions of low velocity (high $\sigma$ and $\varepsilon_{a}$ ) located toward the top of the model represent regions of fine grain size and thus high moisture retention. At the bottom, the low velocity region represents the capillary fringe and the water table. The higher velocity areas then represent regions of low moisture content (i.e., coarser sands and gravels that have low moisture retention capability).

The synthetic EM results for this model were computed using the 3D full wave equation modeling scheme of Wang and Tripp (1997) for a source and receiver sampling interval of $0.25 \mathrm{~m}$ arranged vertically within the boreholes. The source was first located in the left well at $1.0 \mathrm{~m}$ depth, while the receiver was first located in the right hand well at $1.5 \mathrm{~m}$ depth in a pattern similar to the field data described below. The synthetic first arrival times were then determined and inverted to produce the image shown in Figure $1 \mathrm{~b}$. Notice that we have recovered a smoothly varying image which maintains the general 
trends of the structure. However, there is some smearing of boundaries present in the image. This smearing is due to the smoothness constraints that are imposed within the inversion scheme, and also the imaging limitations of the cross-borehole imaging geometry. The latter comment refers to the fact that that in order to exactly recover an image of the region of interest, the data collected during the experiment must completely surround the region (Kak and Slaney, 1988). Because we only have data on two sides of the region of interest (i.e., the two boreholes), image smearing results.

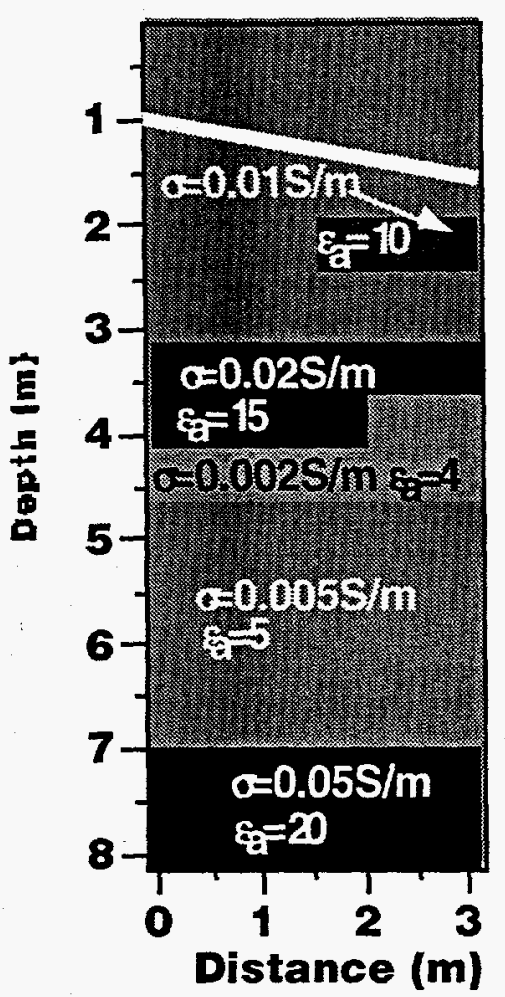

(a)

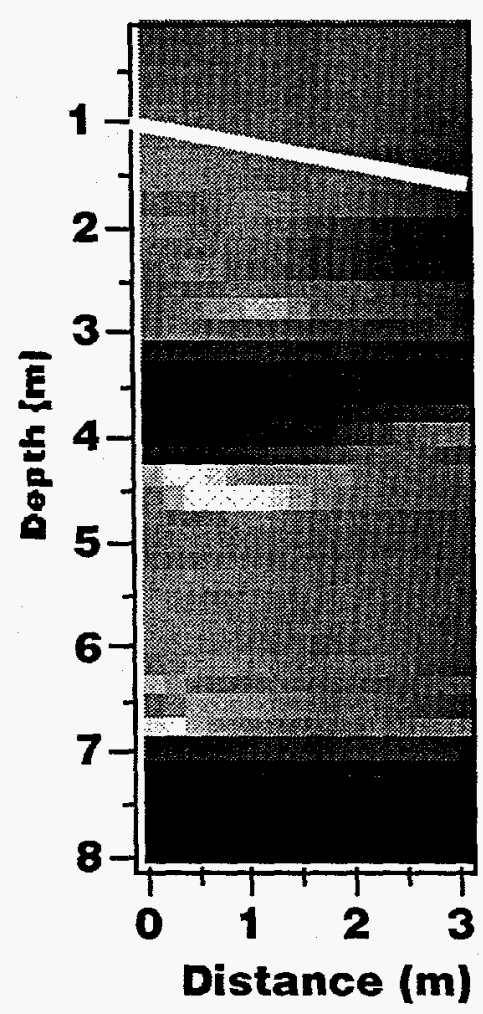

(b)

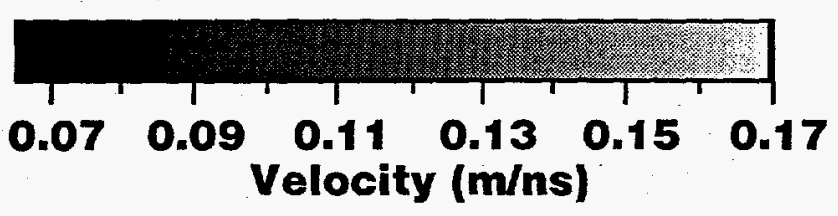

Figure 1 - (a) Velocity and electromagnetic properties model employed in the theoretical study. The velocity of each region is given by the gray scale. The electromagnetic properties $\left(\sigma\right.$ and $\left.\varepsilon_{a}\right)$ that were input into the scheme of Wang and Tripp (1997) are listed in each region. (b) Velocity image produced by inverting the synthetic data generated by the model in (a) using the scheme of Aldridge and Oldenburg (1993). The white lines across the tops of the images designate the boundary above which no data were synthesized. 
In Figure 2a we have converted the EM model shown in Figure 1a into moisture content using Equation 21 in Sen et al. (1981);

$$
q=\frac{\varepsilon_{m}-\varepsilon_{a}}{\varepsilon_{m}-\varepsilon_{w}}\left(\frac{\varepsilon_{w}}{\varepsilon_{a}}\right)^{1 / 3} .
$$

Here $\varepsilon_{m}$ represents the apparent dielectric constant of a dry, air filled quartz sand which we have assumed to have a value of 3 , and $\varepsilon_{w}$ is the dielectric constant of water which is 80. Notice that to force the moisture content to zero, $\varepsilon_{a}$ must be equal to $\varepsilon_{m}$. Thus this expression is correct in the low-moisture-content limit. If we compare this to Topp's equation, we see that substituting $\varepsilon_{a}=3$ into equation (2) will yield a moisture content of $3 \%$ when the rock is dry (i.e. when $\varepsilon_{a}=\varepsilon_{m}$ ), and that the magnitude of this error will increase as $\varepsilon_{m}$ increases. Thus we can see that for this example, Topp's equation breaks down at low moisture contents, which agrees with the conclusions of the original laboratory study (Topp et al, 1980). Because of the more accurate results produced by equation (3) for low moisture contents, we believe Figure 2a represents a more accurate representation of the model moisture content than would result if we employed Topp's equation. However, for higher dielectric constants, say $\varepsilon_{a}=20$, the two expressions produce almost exactly the same result. Finally, we must point out that expression (3) requires that we have some knowledge of the dry-rock dielectric constant. Because we often do not have this knowledge about the soils at a particular site, and because Topp's equation is accurate at higher moisture contents, we will employ equation (2) with equation (1) to convert images of velocity to moisture content with the realization that it will be in error for lower values.

Figure $2 \mathrm{~b}$ shows the moisture content image that results by applying equations (1) and (2) (Topp's approach) to the velocity image shown in Figure 1b. Notice that in general we have recovered the spatial variation of the moisture content, although we do not reproduce the sharp boundaries between different units. Again, the latter is due to the smoothing and smearing nature of the imaging process. In addition, notice that for those regions of low moisture content $(q<10 \%)$ the imaged values (Figure $2 \mathrm{~b}$ ) are greater than those in the model produced via the mixing law (Figure 2a). This again illustrates how these two approaches for converting apparent dielectric constant to moisture content differ for low moisture content, with Topp's equation overestimating the moisture content in these cases. This simplistic example illustrates that we can recover the spatial variability of the moisture content distribution between two wells using Topp's approach to processing cross-borehole GPR velocity images. However the exact values may be suspect, especially at low moisture contents.

\section{EXPERIMENTAL SITE DESCRIPTION AND INSTRUMENT LAYOUT}

To test the feasibility of collecting cross-borehole GPR data, as well as other geophysical data for recovering in situ moisture content in a real world environment, measurements are being made at a hydrologic/ geophysical vadose zone field site in 
Socorro, New Mexico. The field site has been installed into relatively unconsolidated, heterogeneous fluvial deposits consisting of gravel, sand, and clay of fairly high hydraulic permeability. The dimensions of the site are 10 meters by 10 meters with PVC cased subsurface access tubes emplaced to a maximum depth of 13 meters (Figure 3). GPR measurements will only be collected along the southwest-northeast diagonal which includes four access tube pairs. This limited amount of data is partly due to influences from hydrological instrument cables which are permanently installed. To avoid fast travel time paths along the cables which could contaminate the GPR measurements, the cables from these hydrologic probes were routed away from the southwest-northeast diagonal.

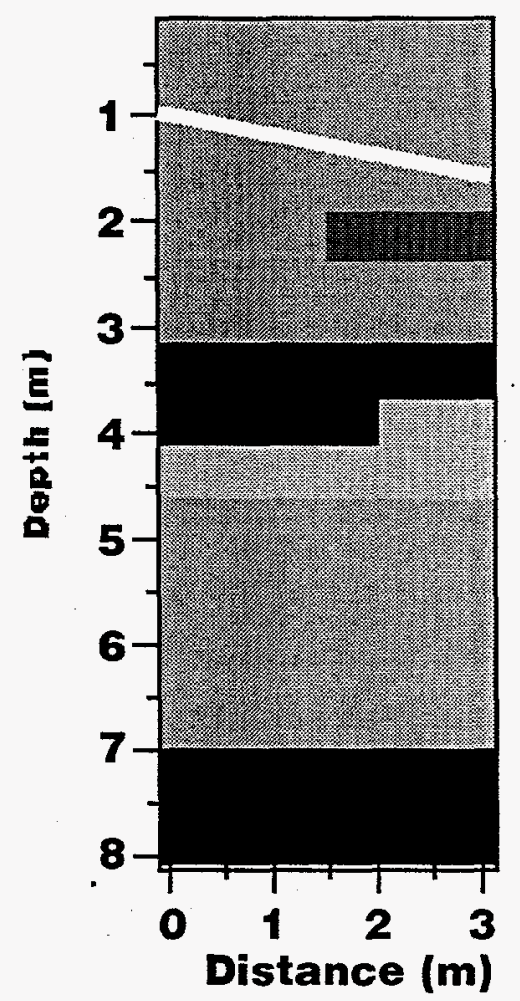

(a)

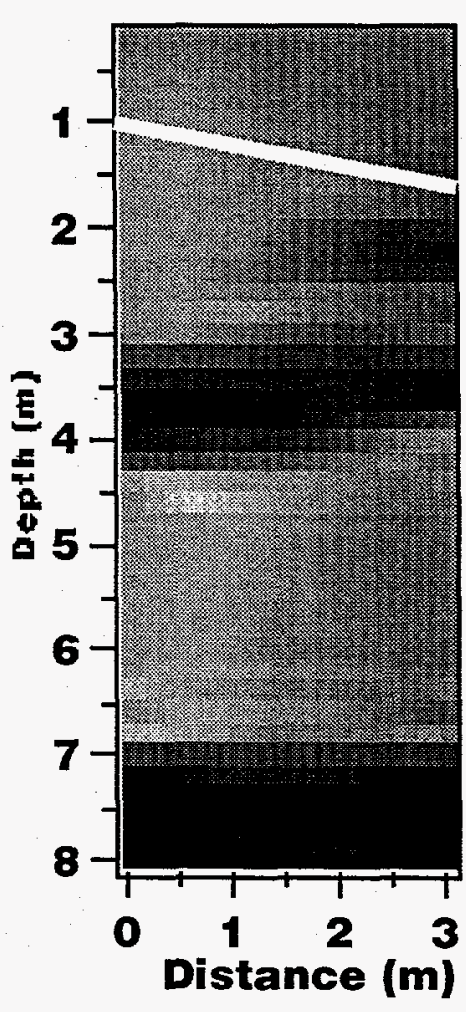

(b)

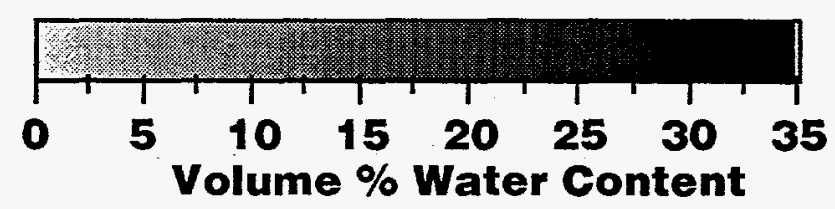

Figure 2 - (a) The moisture content model corresponding to the electromagnetic properties given in Figure 1a, converted via equation (3). (b) Moisture content estimate generated from Figure 1b via Topp's equation (Topp et al., 1980). The white lines across the tops of the images designates the boundary above which no data were synthesized.

GPR data collection parameters include using a center frequency of $100 \mathrm{MHz}$ along with a 0.25 meter spatial sampling interval for both the transmitter and the receiver. In the experiment described below, the transmitter was started at a depth of $1.25 \mathrm{~m}$ while 
the receiver was started at a depth of $1.5 \mathrm{~m}$. However, in the future the GPR measurements will begin at a depth of $0.25 \mathrm{~m}$. To ensure accurate data in the presence of instrument drift, calibration files were and will be collected after every tenth transmitter position. Although this causes some additional difficulty within the processing, it was found to cause better image results, especially for those positions when both the source and receiver were near the bottom of the boreholes. Finally, the acquisition angle between the source and receiver never exceeds 45 degrees as for angles greater than this aforementioned problems associated with the hydrologic sensor cables were noticed.

Neutron probe measurements are also being collected within all access tubes shown in Figure 3. Neutron probe measurements are an accepted and common method of measuring moisture content immediately around the borehole (Wilson et al., 1995), and thus will provide a check on the moisture content estimates provided by the GPR and other methods. Measurements will be collected using a 0.25 meter sampling interval for easy comparison to the GPR images.

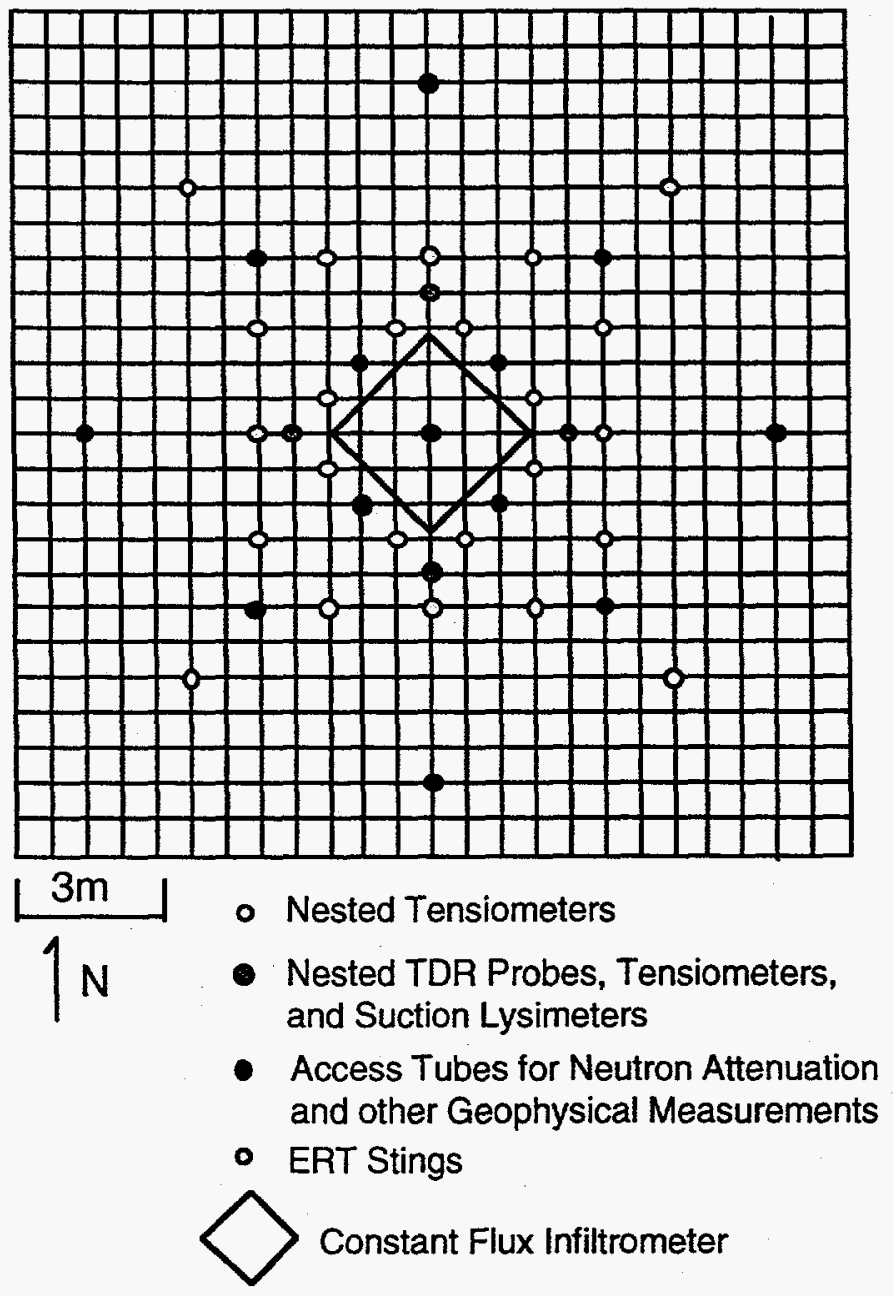

Figure 3 - Plan view showing the locations of the hydrologic instruments and boreholes used for neutron and cross-borehole GPR measurements. 
Infiltration will occur on a 3 by 3 meter constant flux infiltration pad and the wetting front will be monitored by both various permanently installed hydrological and geophysical instruments as well as the neutron and GPR. The hydrological instruments that have been installed at the field site include tensiometers, time domain reflectometry (TDR) probes, and suction lysimeters. In addition to the GPR, 3D electrical resistance tomography (ERT) is being employed to estimate moisture content. Outside of the infiltrometer, a no-flow top boundary condition has been established by overlaying the whole site with a tarp to eliminate both evaporation and precipitation.

\section{BASELINE DATA}

The in situ moisture content image from baseline GPR data is shown in Figure 4. Here the GPR image is being compared to neutron probe data that were collected in the five boreholes employed in the GPR survey. High counts or peaks in neutron data correlate to high moisture content. The neutron probe data, plotted as the black curves in Figure 4, seem to correlate well with the GPR image. Specifically, high counts in the neutron probe data at depths of 4 and 5.5 meters depth agree with zones of high moisture content in the GPR image. From core samples collected in boreholes near the profile, we know that a silt layer is located between 3.5-4 meters depth, a clay layer occurs at 5.5 meters depth, and the rest of the section is dominated by sands and gravels. Fine grained sediments tend to have higher moisture contents than the surrounding sands thus the GPR and neutron data appear to be sensing increases in moisture content. Other peaks in the neutron probe data correlate with less continuous regions of higher moisture content within the GPR image. For example, there is a peak in the neutron probe data in borehole NINE at 7 meters depth where the GPR data indicates an increase in moisture content from 5 to 11 percent. In addition, there is another neutron peak in N2NE at 8 meters depth where the GPR image indicates an increase in moisture content from 5 to 8 percent. Finally, both the GPR image and neutron data show very low moisture content values near the surface, and the 'layers' of high moisture content at 4 and $5.5 \mathrm{~m}$ depth become drier as one progresses across the site from the N2SW borehole to the site of the N2NE borehole. These results show that the cross-borehole GPR images can non-destructively provide realistic images of the spatial variability of subsurface moisture content.

\section{CONCLUSIONS AND FUTURE WORK}

Preliminary results for numerical experiments and preliminary field measurements indicate that GPR can be used to estimate the in situ moisture content distribution in a heterogeneous environment. However, theoretical simulations have verified that the relationships between apparent dielectric constant and moisture content become less accurate at low moisture content when using Topp's equation (Topp et al, 1980). Future accuracy checks of the cross-borehole GPR method will include comparing the images to calibrated neutron probe measurements, as well as obtaining baseline moisture content measurements from hand samples in the lab.

To complete this study of better defining subsurface hydrologic properties in situ, cross-borehole GPR data acquisition will continue once infiltration is started at the 
Socorro test site. In addition, we are currently working with researchers from the University of Arizona to use the GPR data as an input to their 2-D hydrologic inverse code.

\section{ACKNOWLEDGMENTS}

This work was performed at Sandia National Laboratories and New Mexico Institute of Mines and Technology with funding provided by the U.S. Department of Energy's Environmental Management Science Program. Sandia is a multiprogram laboratory operated by Sandia Corporation, a Lockheed Martin Company, for the United States Department of Energy under Contract DE-AC04-94AL85000.
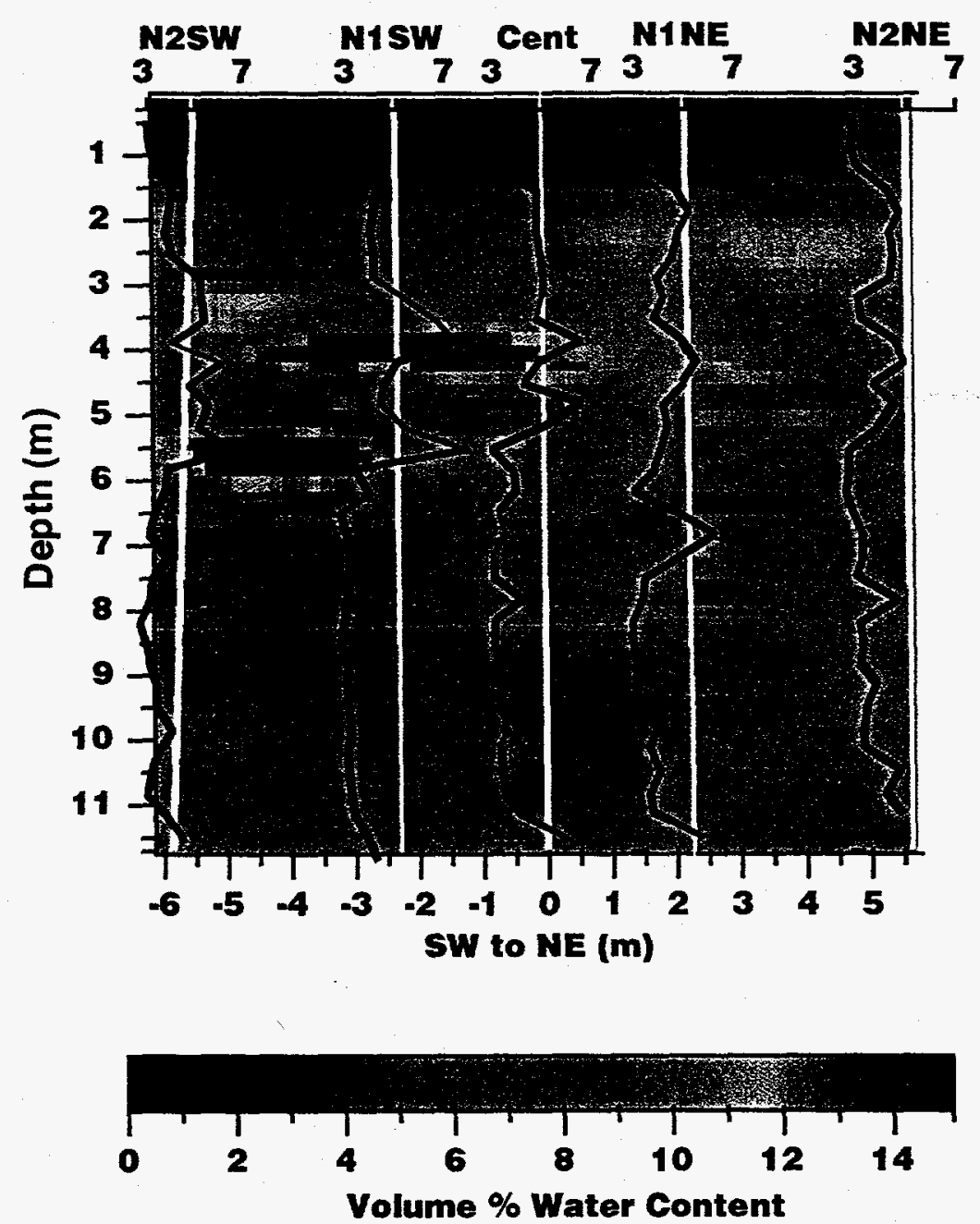

Figure 4 - Pre-infiltration moisture content image from cross-borehole GPR data and uncalibrated neutron logs collected at the Socorro vadose zone test site. The white lines on the diagram represent the well locations, and the black curves are the neutron logging results $\left(1000^{*}\right.$ counts). 


\section{REFERENCES}

Aldridge, D.F. and Oldenburg, D. W., 1993. Two-dimensional tomographic inversion with finite-difference travel times. Journal of Seismic Exploration, 2:257-274.

Eppstein, M. J. and Dougherty, D. E., 1998. Efficient three-dimensional data inversion: Soil characterization and moisture monitoring from cross-well ground-penetrating radar at a Vermont test site. Water Resources Research, 34:1889-1900.

Greaves, R. J., Lesmes, D. P., Lee, J. M., and Toksoz, M. N., 1996. Velocity variations and water content estimated from multi-offset, ground-penetrating radar. Geophysics. 61:3:683-695.

Hubbard, S. S., Rubin, Y., and Majer, E., 1997. Ground-penetrating-radar-assisted saturation and permeability estimation in bimodal systems. Water Resources Research, 33:5:971-990.

Kak, A.A., and Slaney, M.S., 1988, Principles of Computerized Tomographic Imaging, IEEE Press.

Sen, P.N., Scala, C., and Cohen, M.H., 1981. A self-similar model for sedimentary rocks with application to the dielectric constant for fused glass beads. Geophysics,46:5:781-795.

Topp, G. C., Davis, J.L. and Annan, A.P., 1980. Electromagnetic determination of soil water content: Measurements in coaxial transmission lines. Water Resources Research, 16:3:574-582.

van Genuchten, M.T., 1980. A closed-form equation for predicting the hydraulic conductivity of unsaturated soils. Soil Sci. Soc. Am. J., 44, 892-898.

Vidale, J., 1988 Finite-difference calculation of travel times. Bull. Seism. Soc. Am., 78:2062-2076.

Wang, T., and Tripp, A. C., 1997, FDTD simulation of EM wave propagation in 3-D media. Geophysics, 61:1:110-120.

Wilson, L.G., Everett, L. G., and Cullen, S. J., 1995. Handbook of Vadose Zone Characterization and Monitoring. CRC Press.

Zhang, J., and T.-C. J. Yeh, 1997. An iterative geostatistical inverse method for steady flow in the vadose zone. Water Resources Research, 33:1:63-71. 